\title{
Helena: representações de práticas de leitura e configurações do leitorado oitocentista brasileiro no romance machadiano
}

Patrícia Kátia da Costa Pinal UESC - Ilhéus, BA

Vânia Lúcia Menezes Torgal UESC - Ilhéus, BA

Resumo: Este artigo estuda as representaçôes de atos de leitura presentes no romance Helena, de Machado de Assis, interpretando-as como instrumentos capazes de configurar o leitorado brasileiro oitocentista. Para tanto, são analisadas comparativamente as cenas de leitura protagonizadas por D. Úrsula, Helena e Estácio, tendo em vista as relaçôes sociais, políticas e históricas que cercam a trama e as personagens recortadas. São observados modos de ler "masculinos" e "femininos", que viabilizam a reflexão sobre o lugar da mulher nesse Brasil ainda patriarcal e já caminhando para o capitalismo. O objetivo é investigar de que maneira esse romance machadiano funciona para formar e manter padrões de gosto pela leitura literária. A argumentação se sustenta, fundamentando-se nas idéias de Wolfgang Iser, Roger Chartier, Marisa Lajolo, Regina Zilberman, Hélio Guimarães, entre outros.

Palavras-chave: atos de leitura, representação literária, romance machadiano, leitor. 
Pertencente à fase da produção machadiana em que o narrador, já um tanto cansado de conduzir pela mão seu rarefeito e "borboleteante" público leitor, começa a dar-lhe divertidos piparotes, desafiando-o a vôos mais altos, o fragmento em epígrafe aponta para a complexidade da composição literária, quando compreendida não somente como produto da genialidade artística de um indivíduo, mas como objeto transitivo, que demanda a introjeção de uma alteridade assustadora, porque desconhecida em suas particularidades - o leitor.

O leitor se configura como um grande problema para os escritores oitocentistas brasileiros, seja por sua rarefação, seja por sua pouca ou nenhuma intimidade com o impresso. Rarefação porque nossa sociedade, em suas raízes coloniais, arredou de si a educação sistemática dos mais amplos segmentos populacionais: ainda hoje são imensos os contingentes de analfabetos. Conseqüentemente, mesmo após a Independência, quando se buscou construir literária e culturalmente a nação brasileira, quando se começou a pensar em estabelecer um sistema educacional mais abrangente, as fatias populacionais atingidas por essas iniciativas foram impelidas a descartar séculos de práticas culturais marcadas pela oralidade para incorporar a seu cotidiano aquelas próprias das culturas mediadas pela escrita.

O narrador de Memórias póstumas, ao provocar seus leitores, traça um esboço dos padrões de gosto que regiam a produção e a recepção dos textos literários nessa época:

Tu tens pressa de envelhecer, e o livro anda devagar; tu amas a narração direita e nutrida, o estilo regular e fluente, e este livro e o meu estilo são como os ébrios, guinam à direita e à esquerda, andam e param, resmungam, urram, gargalham, ameaçam o céu, escorregam e caem...

Ele sabe que a maior parte do leitorado brasileiro é composto de leitores apressados e afeitos a uma leitura panorâmica - aqueles que, segundo Eco (1994), desejam chegar rapidamente ao fim do bosque, fazendo a leitura esperada pelas práticas da simetria, da paráfrase, da re-produção, do esperado. No momento em que o livro citado vai a público, já o narrador machadiano estabelece uma nova forma de se relacionar com seu possível interlocutor: ${ }^{3}$ provocando-o, através de

1. ZUMTHOR, 1993; PINA, 2002, 2006.

2. MACHADO DE ASSIS, 1957 [1880], p. 222.

3. GUIMARÃES, 2004. 
sua implicitação no texto, a qual viabilizaria um meio alternativo e engraçado de transformá-lo em um "bom leitor" - a referência à instabilidade do estilo, perceptível no trecho acima, traduz, acima de tudo, uma proposta de leitura que, cambiante, instiga, convida a penetrar no bosque pelos atalhos, por paradas acompanhadas de resmungos. Embora todos os seus romances tragam esse diálogo ficcional bemhumorado com o leitor empírico, Machado de Assis arquiteta um tom diferenciado entre os chamados romances da primeira fase e os da segunda.

De Ressurreição a Iaiá Garcia, os diálogos com o leitor são escassos. Em seu lugar, o narrador machadiano trabalha com variadas representações de cenas de leitura e diferentes indicações do gosto literário da época. Trata-se, segundo entendemos, de uma estratégia baseada na exposição de modelos a serem seguidos e, ou transgredidos: o leitor empírico, de acordo com o processo de identificação que estabeleceria com personagens e situações, seria levado a perceber modos adequados e proveitosos de ler (bem como seu contrário), "aprendendo" as melhores e as piores leituras, até por acompanhar os efeitos e as conseqüências dos livros lidos pelas personagens.

Este artigo se propõe, então, a analisar essas representações de práticas de leitura no romance Helena. Publicada em folhetim, n'O Globo, em 1876, a narrativa em tela desenha perfis de um leitorado masculino e de um feminino, através de imagens definidoras dos paradigmas aceitáveis de leitura para mulheres e homens desse Brasil cindido entre o patriarcalismo ruralista e o capitalismo urbanizador, característico da segunda metade do dezenove.

Em "A história da leitura de Gutenberg a Bill Gates", Martyn Lyons lê uma metáfora criada por Michel de Certeau, de forma bastante interessante para a investigação aqui desenvolvida: "O leitor é um invasor, rastejando pela propriedade de outrem atrás de propósitos nefastos”. "Lyons retoma Certeau para discutir os fundamentos das teorias da recepção, como as desenvolvidas por Jauss e Iser-embora não os cite diretamente-, segundo os quais os textos trazem estruturas que enredam e conduzem o leitor empírico. Ele discute esse ocultamento do leitor no texto, sua implicitação, e sua capacidade de comandar os processos de leitura.

Na seqüência da citação acima recortada, Lyons reflete sobre as relações texto/leitor, numa perspectiva que me parece revestir este último do poder de reinventar a obra lida pelo próprio processo de leitura:

4. LYONS, 1999, p. 11. 
A propriedade não é dele; a paisagem foi feita por outras mãos. Porém, enquanto não é apanhado, ele toma o que deseja - uma lebre aqui, um tordo ali, até mesmo um cervo, com sorte -, fugindo sem deixar rastros na página. Desse modo, o leitor individual insinua seus significados e objetivos dentro do texto de outrem. Cada leitor individual tem meios silenciosos e invisíveis de subverter a ordem dominante da cultura de consumo.

Concordamos com a potencial habilidade de reinvenção da obra no ato da leitura, mas entendemos que tal processo funciona como um intercâmbio, não como um assalto. A interação mediada pela escrita e pela leitura permite ao leitor pressuposto ver o que o narrador não vê. Esse leitor, de sua posição de exterioridade, produziria o sentido transgressor esperado pelo narrador - ou não.

A perspectiva esboçada por Martyn Lyons certamente deriva de sua posição de historiador da leitura, que se interessa por leitores reais, cujos registros de leitura foram documentados de alguma forma. ${ }^{6}$ No entanto, as metáforas por ele usadas em sua apropriação do pensamento de Certeau erigem o ato de ler como subversivo e independente do texto. Subversivo é mesmo, mas não necessariamente em relação à obra, uma vez que ler é atravessar as múltiplas textualidades inscritas na palavra impressa. A palavra, como a moeda, tem duas faces.

Wolfgang Iser traz para os estudos literários a investigação sobre os mecanismos textuais que conduzem a interação da obra com o leitor. Há entre ambos uma assimetria que viabiliza o diálogo. Para Iser, por meio da ficção, o leitor pode atravessar as fronteiras do mundo instituído, uma vez que ele o refaz, antropofagizando a realidade. Segundo ele, o texto ficcional não é pleno em si, carrega lacunas que implicam uma projeção do leitor. A leitura surge, então, como uma atividade comandada, sim, pelo texto:

[...] a relação entre texto e leitor só pode ter êxito mediante a mudança do leitor. Assim o texto constantemente provoca uma multiplicidade de representações do leitor, através da qual a assimetria começa a dar lugar ao campo comum de uma situação. Mas a complexidade da estrutura do texto dificulta a ocupação completa desta situação pelas representações do leitor. O aumento da dificuldade significa que as representações devem ser abandonadas. Nesta correção, que o texto impõe, da representação

5. LYONS, 1999, p. 11.

6. LYONS, 1999, p. 10. 
mobilizada, forma-se o horizonte de referência da situação. Esta ganha contornos, que permitem ao próprio leitor corrigir suas projeções. Só assim ele se torna capaz de experimentar algo que não se encontrava em seu horizonte.

Pela própria indeterminação, a relação texto/leitor abre incontáveis possibilidades de comunicação, que dependem dos mecanismos textuais de controle. Os vazios, as negações, as supressões, as cesuras, as imagens, os cerzidos do texto, enfim, dão o lugar do leitor, quebrando o fluxo textual, interrompendo a articulação discursiva seqüencial. Dessa forma, o texto pode provocar o imaginário do leitor, dinamizando o impresso.

Retomamos o que afirma Martyn Lyons: parece-nos que ele reage às reflexões do teórico alemão, e a outras similares, por se manterem muito próximas da obra, dependentes dela até, e por somente estudarem o leitor e a recepção através do texto literário. A rápida discussão aqui estabelecida não pretende reavivar polêmica alguma, nem defender este ou aquele ponto de vista. São dois os propósitos: situar teoricamente este artigo e justificar sua abordagem do romance machadiano.

Em primeiro lugar, é fundamental esclarecer que aqui literatura é entendida como linguagem. Parece óbvio, mas não é. Isso significa que, sob a ótica deste texto, estudar o leitor e a leitura implica estudar a interação entre a obra e seu interlocutor. O leitor empírico, aqui, não será visualizado por meio de entrevistas ou estatísticas. Ele será enfocado a partir das representações textuais, ou melhor, a partir de diferentes ficcionalizações de leitores e de atos de leitura. Trocando em miúdos: como a nossa perspectiva é a da relação texto/leitor, este último não será abordado como aquele que toma o texto de assalto, mas como o indivíduo pressuposto pela obra, o qual tem franqueado seu acesso a ela, podendo abrir diálogo a qualquer momento, sem fugas, apenas com as necessárias negociações que produzem diferentes sentidos para o lido. Não que os "meios silenciosos e invisíveis" usados pelo leitor teorizado por Lyons sejam descartáveis; ao contrário, fazem parte das transações que, sob nossa ótica, constituem o ato de leitura.

Neste artigo, as "outridades" acarretadas pelo texto estabelecem padrões de interação provocados pela palavra literária: autor/obra/leitor são indissociáveis e são históricos, marcados pelo tempo, pelo espaço, pela cultura. Autor/obra/leitor exercem as funções intercambiáveis de caça e caçador.

7. ISER, 1979, p. 88-89. 
No século XIX brasileiro, criou-se a consciência da escassez de leitores tanto para as obras literárias importadas da Europa, como para as produzidas aqui, o que pôs em xeque a literatura como veículo de construção simbólica da nação e do nacionalismo, missão máxima do escritor brasileiro. Formar o gosto pela leitura, colocar leitores como modelos de cidadãos foi, então, um meio de fortalecer o sentimento de brasilidade. ${ }^{8}$

No entanto, é na década de 1870, momento de publicação de Helena, que o projeto nacionalista romântico começa a ruir e vai sendo engendrada uma outra forma de se estabelecerem as relações entre autor/texto/público: o leitor não é mais uma figura que se esvai ao primeiro olhar, é uma realidade, esquiva, sim, mas objetiva e fundamental para o mercado cultural de então.

Por conta dessa "concretização" do leitor empírico, romances como Helena tentam desenhá-lo, em lugar de desafiá-lo, tematizando, implicitamente, a assimetria a que alude a teoria iseriana. Recorrer, então, às práticas de leitura conhecidas, representando-as na trama narrativa, poderia funcionar como uma interessante "isca" para esse grupo arisco.

Nossa sociedade se queria progressista e burguesa, mas escorregava pelos meandros do patriarcalismo monárquico e ruralista. Simultaneamente, construir imagens de leitor e de leitura de matriz burguesa seria uma forma de, por um lado, propor novos paradigmas de comportamento e consumo cultural, por outro, dialogar com as expectativas que se criavam por aqui.

Walty, Fonseca e Cury afirmam, em Palavra e imagem, que o impresso conduz o leitor, a palavra guia suas reflexões:

A leitura é um processo associativo que promove a interação 'escrita e imagem' em diversos sentidos: a imagem propriamente dita; a que ilustra textos verbais; aquela construída pelo leitor quando lê, que tanto pode restringir-se ao momento real de produção de sentido, como pode ser base de outras citações. (...). Além disso, textos verbais ou pictóricos exibem imagens do ato de ler, apreendendo o leitor nas malhas discursivas. Representações do livro e da atividade de leitura em diversas produções culturais possibilitam-nos também refletir sobre seu lugar social, tanto numa dimensão espacial quanto temporal, delineando o perfil do leitor no imaginário da sociedade.

8. GUIMARÃES, 2004, p. 32.

9. WALTY; FONSECA; CURY, 2006, p. 7. 
Ao ler um romance, então, o leitor se apropria das imagens propostas na tessitura narrativa, concretizando-as pela particularidade de seu imaginário. O romance constrói e propõe uma cena, por exemplo, que é reconstruída a cada ato de leitura. Nesse processo, as habilidades e competências do leitor empírico entram no jogo e determinam os caminhos imaginários da recepção.

Em Helena, por exemplo, logo após a chegada da protagonista à casa do Conselheiro Vale, D. Úrsula desenha uma prática de leitura comum na época em que ocorre a ação romanesca e ainda na década de 1870, quando o livro é publicado:

Na manhã seguinte, Estácio levantou-se tarde e foi direito à sala de jantar, onde encontrou D. Úrsula, pachorrentamente sentada na poltrona de seu uso, ao pé de uma janela, a ler um tomo do Saint-Clair das Ilhas, enternecida pela centésima vez com as tristezas dos desterrados da ilha da Barra; boa gente e moralíssimo livro, ainda que enfadonho e maçudo, como outros de seu tempo. Com ele matavam as matronas daquela quadra muitas horas compridas do inverno, com ele se encheu muito serão pacífico, com ele se desafogou o coração de muita lágrima sobressalente. ${ }^{10}$

A descrição que o narrador faz da postura da leitora associa imediatamente o ato de leitura ao ócio feminino burguês desejado pela sociedade. De sua confortável posição física e social, D. Úrsula pode lamentar as ficcionais desgraças alheias e até divertir-se com elas, num movimento catártico. Para Marisa Lajolo, "[é] por isso que se lê romance: para viver por empréstimo, e nesta vida emprestada aprender a viver". ${ }^{11}$ E é preciso se reinventar a cada leitura, ainda que seja do mesmo livro. Portanto, não há uma leitura que não chame a uma outra escritura. Não há uma leitura que não seja responsável, que não clame por uma resposta.

Esse aspecto relevante das práticas de leitura oitocentistas vem gravado no fragmento acima: a leitura constante e repetida de um só livro. D. Úrsula lia o romance apontado pela "centésima” vez. Hipérboles à parte, pode-se perceber aí que os livros eram relidos inúmeras vezes, desde que satisfizessem a todas as injunções sociais, especialmente em se tratando da "leitora", o que nos parece desenhar uma prática "feminina" de leitura, a saber, refazer o caminho do mesmo livro, desde que sancionado pela família, pela igreja...

10. MACHADO DE ASSIS, 1959 [1876], p. 29.

11. LAJOLO, 2004, p. 28. 
Em Helena, a ação retrocede até a década de 1820, retorna até 1850 e o romance é publicado em 1876: esse é o período em que a sociedade patriarcal herdada da colônia vai sendo infiltrada pelas camadas burguesas, por intelectuais, jornalistas, funcionários públicos etc. Nesse romance, a estratificação social é rígida e propõe estratégias de resistência a essas mudanças, como a "retórica da aparência" a que se refere Regina Zilberman, a qual demanda ser transgredida e atravessada no ato da leitura.

A construção imaginária dos valores que cercam o ato de ler agrega a este a idéia de que é necessário estar relaxado para tomar de um livro e saborear suas páginas e que é preciso ter tempo sobrando para isso. Tanto há uma ratificação "inofensiva" dos valores patriarcais então vigentes, como há o aceno para uma nova e diferente ordem social, em que à mulher caberia, ainda que de maneira incipiente, a função de pensar por si mesma. A leitura surge, aí, como atividade que preenche de forma salutar o ócio próprio das classes abastadas, unindo familiares e amigos numa só atividade de lazer.

A hipótese de que essas representações de cenas de leitura seriam eficientes estratégias de contato com o arredio leitorado brasileiro oitocentista, tem respaldo na Poética, de Aristóteles: "Imitar é natural ao homem desde a infância - e nisso difere dos outros animais, em ser o mais capaz de imitar e de adquirir os primeiros conhecimentos por meio da imitação - e todos têm prazer em imitar". Pensamos ser bastante provável que tais cenas, protagonizadas por personagens significativos, poderiam provocar algum tipo de desejo de imitação por parte de leitores e leitoras de primeira, segunda ou até terceira viagem. Por aí, os textos capturariam (ou não) esse leitor/essa leitora em suas malhas.

Assim, entendemos que o texto literário não apenas traz implícito seu leitor pressuposto, mas ele o representa, muitas vezes, em atos de leitura que, ao serem desdobrados e reinventados pelo leitor empírico, podem provocar e, ou desenvolver o gosto pela leitura literária. E, como afirma David Olson, "[...] nossas representações têm como nos dizer, nos ditar, o que somos e onde estamos". ${ }^{14}$ Nós nos vemos naquilo que é representado e com esses objetos nos identificamos, seja para aceitá-los, seja para recusá-los, seja para discuti-los.

12. ZILBERMAN, 1989, p. 100.

13. ARISTÓTELES, 1996, p. 33.

14. OLSON, 1997, p. 9 
Nesse trânsito, o leitor empírico põe em ação seus próprios paradigmas de leitura. Assim, a leitura literária pressupõe uma espécie de palavra hipertextual, porque implica uma rede de textos para se efetivar - e essa própria rede pode vir representada na obra, como baliza para a realização da leitura: "As imagens, podese concluir, carregam uma significação cultural, com marcas geográficas, afetivas, religiosas etc., o que permite ao leitor leituras também múltiplas e relacionamentos intertextuais infinitos". ${ }^{15}$ Representar, então, imagens de atos de leitura pode ser lido como uma estratégia autoral para captar a atenção do leitor, promovendo tanto a "educação" do mesmo para a leitura literária, como a construção de hábitos de consumo do impresso. Retomando Olson, "Num certo sentido, a leitura exige de todo leitor que ele se torne um ator; o leitor precisa 'interpretar' as linhas que lê [...]"

No século XIX, em particular no oitocentos brasileiro, em função de séculos de trânsitos culturais marcados pela oralidade, uma vez que a Metrópole controlou e cerceou a produção e a circulação do impresso por aqui, impedindonos de ter a escrita como mediadora de nossas relações sociais e culturais, construiuse uma descontinuidade de horizontes entre escritores e leitores, até porque, vale repetir, esses últimos primaram pela raridade. As idéias burguesas européias, com raízes na Ilustração, como afirma Roberto Schwarz, foram, aqui, ornamentais, funcionando como marcas de superioridade social, não como pressupostos que sustentavam as relações sociais. ${ }^{17}$

Dessa forma, a sociedade que se origina dessa situação implicou uma relativização das diferentes ideologias, uma desqualificação do pensamento, e o leitor tornou-se não uma solução para o mercado livreiro em ascensão, mas um problema para escritores, editores etc. Sua implicitação e, ou representação nas formas literárias em circulação no país foi uma estratégia para que se formassem e mantivessem círculos de indivíduos interessados no consumo do texto literário.

Cabe ressaltar que, como afirmam Regina Zilberman e Marisa Lajolo, a figura do leitor é uma concepção burguesa, determinada pela conjunção de práticas sociais relacionadas tanto ao antropocentrismo renascentista, como à imprensa, à escola etc. O leitor nasce com a sociedade moderna e assume as identidades que ela suscita:

15. WALTY; FONSECA; CURY, 2006, p. 114.

16. OLSON, 1997, p. 125.

17. SCHWARZ, 1981, p. 16-18. 
Disso resultaram duas noções: de um lado, a noção de público, massa coletiva e anônima que, não obstante o anonimato, pode ter vontade própria e direção definida, incidindo em linhas de ação que a literatura, em parte ou no todo, acata ou não; de outro, a noção de leitor, indivíduo habilitado à leitura, com preferências demarcadas, figura que o escritor busca seduzir, lançando mão de técnicas e artifícios contabilizados pela crítica e história da literatura. ${ }^{18}$

Os ficcionistas brasileiros da primeira metade do século XIX infantilizam o leitor, construindo narradores tutelares e paternalistas que espelham as relações sociais mais amplas da época. Suas figurações de leitor e de leitura, projetando um leitor idealizado, propõem paradigmas do ato de ler a serem seguidos. Até porque essas sutis práticas pedagógicas, que dariam sustentação à ordem econômica vigente, desenhavam um leitor que poderia ler e atuar pela simetria, confirmando o poder hegemônico de então.

Com as transformações sofridas pelo evanescente leitorado brasileiro, tais estratégias narrativas ganharam diferentes roupagens. A visibilidade conquistada pela mulher como leitora levou os escritores a incorporarem aos romances, gênero predileto desse público específico, mudanças estruturais, bem como alterações nos modos de produção e circulação do impresso.

Segundo Hélio Guimarães, na década de 1870,

[...] a imprensa torna-se mais atuante, a atividade editorial ganha maior regularidade e profissionalização e as condições reais do país tornam-se mais conhecidas, tudo isso contribuindo para deixar mais claras as proporções diminutas do público consumidor de literatura no Brasil. ${ }^{19}$

A percepção da exigüidade do leitorado brasileiro atravessa o final do século e leva Machado de Assis, em Memórias póstumas de Brás Cubas, a desenhar um desconsolado quadro de nossa vida intelectual: "Capítulos compridos quadram melhor a leitores pesadões; e nós não somos um público in-folio, mas in-12, pouco texto, larga margem, tipo elegante, corte dourado e vinhetas... principalmente vinhetas..." ${ }^{20}$ A falta de fôlego do público leitor, seu despreparo

18. LAJOLO; ZILBERMAN, 1996, p. 9.

19. GUIMARÃES, 2004, p. 32.

20. MACHADO DE ASSIS, 1957, p. 96. 
para uma leitura 'de boa casta', como a feita por Luís Garcia, personagem do romance Iaiá Garcia, que se dedica ao ofício de leitor, apesar da pouca instrução, dos poucos meios e de muitos outros empecilhos, ${ }^{21}$ ficam gritantes no fragmento destacado. O leitor brasileiro não era habituado a fazer "grandes" leituras, ele se formou nas páginas do folhetim e se doutorou nas folhas dos romances europeus adaptados e mal traduzidos que por aqui aportavam. Isso, os leitores "burgueses".

Vale a pena citar o fragmento de Iaiá Garcia em que o narrador define o "leitor de boa casta":

Luís Garcia era homem de escassa cultura, sobretudo irregular; mas tinha os dons naturais e a longa solidão dera-lhe o hábito de refletir. Também ele ia à casa de Jorge, cujos livros lia de empréstimo. Era tarde; já não estava moço; faltava-lhe tempo e sobrava-lhe fome; atirou-se sôfrego, sem grande método nem escrupulosa eleição; tinha vontade de colher a flor ao menos de cada coisa. E porque era leitor de boa casta, dos que casam a reflexão à impressão, quando acabava a leitura, recompunha o livro, incrustava-o por assim dizer, no cérebro; embora sem rigoroso método, essa leitura retificou-lhe algumas idéias e lhe completou outras, que só tinha por intuição. ${ }^{22}$

A definição do bom leitor para Machado de Assis está dada aí: não era necessário ter berço burguês ou aristocrático e ser culto, era fundamental ser concentrado e reflexivo. O bom leitor seria capaz de meditar sobre o lido - poderia "ler levantando a cabeça" -, transformando-se a partir daí, mudando até sua forma de pensar. Outro aspecto importante na citação: Jorge, ainda que não seja exatamente um bom leitor, funciona como multiplicador do gosto pela leitura, pois empresta seus livros. Aliás, é assim que declara seu amor por Iaiá.

$\mathrm{Na}$ obra romanesca machadiana, principalmente nos primeiros romances, a leitura sempre faz a mediação das situações cotidianas, em especial das mais complexas e que definem os rumos da trama e dos personagens.

Em Helena, a matriz patriarcal da sociedade recortada e representada no romance vem definida já na primeira página: todas as ações e personagens giram em torno do Conselheiro Vale. O primeiro ato de leitura representado no livro

21. MACHADO DE ASSIS, 1957, p. 137.

22. MACHADO DE ASSIS, 1957, p. 136-137. 
é 'masculino', envolvendo homens, bens e justiça: é a abertura do testamento do Conselheiro. As mulheres têm papel marginal nessa ação e seu modelo é D. Úrsula.

O testamento constrói na narrativa a personagem protagonista: Helena. É esse ato de justiça e de leitura que 'cria' Helena e lhe dá um lugar na família e na sociedade. Após a sua chegada, os trânsitos familiares ganham maior definição, entre eles as práticas de leitura.

Entendemos que as três personagens que compõem a família do Conselheiro morto representam modos de ler e preferências de leitura bastante significativas e indiciadoras das práticas recorrentes no oitocentos brasileiro.

Em primeiro lugar, fica bem determinado que a leitura é uma forma de preencher as horas ociosas. Esse preenchimento poderia ser positivo ou negativo. Além desses valores morais agregados ao ato de ler, percebe-se, nas representações de cenas de leitura em Helena, a colocação desse ato como algo pertinente apenas às classes abastadas, únicas que podiam ter o luxo do ócio.

Se D. Úrsula tem como hábito a releitura do mesmo livro, sua suposta sobrinha faz um passeio pela pequena biblioteca que carrega em sua mudança do colégio para a casa da família Vale. O interessante é que é uma leitura particular, o que distingue sua prática da de D. Úrsula, que lê na saleta à qual todos têm acesso: "[...] Helena retirou-se ao seu quarto, onde durante três dias passou quase todas as horas, a ler meia dúzia de livros que trouxera consigo, a escrever cartas, a olhar pasmada para o ar, ou encostada ao peitoril de uma das janelas." ${ }^{23}$ Ela, como a tia, lê para encher o tempo vago, mas sua leitura é panorâmica, "borboleteante", lê como se passeasse os olhos pela rua do Ouvidor...

Páginas adiante, estando Estácio a arrumar seu gabinete de leitura, com a ajuda de Helena, ele folheia os livros novos que chegaram e reorganiza as estantes. Nesse trabalho conjunto, às vezes Helena seguia suas próprias idéias para arrumar o local. Ao ver a irmã trabalhando, ele a define: "-Sossega, borboleta!" ${ }^{24}$ Não que as práticas de leitura associadas a Estácio possam caracterizá-lo como um "leitor de boa casta", também ele se deixa flanar pela diversidade do impresso que tem à disposição.

A leitura "em segredo" efetuada por Helena na maioria das cenas, em que é representado o ato de ler, traz a marca do recato feminino, também pode desmenti-lo, pois assemelha-se às práticas de leitura "masculina" representadas

23. MACHADO DE ASSIS, 1957, p. 32.

24. MACHADO DE ASSIS, 1957, p. 89. 
no romance. Ela e Estácio espanejam suas asas sobre os mais variados livros, colhendo de cada um o necessário para os trânsitos sociais deslocados típicos do Brasil oitocentista.

Mais tarde, quando ele viaja para acompanhar a noiva Eugênia, pede a Helena que lhe mande livros, dando-lhe certa autonomia: "Tira da estante oito ou dez volumes, à tua escolha." " Numa inversão das práticas culturais paternalistas, é Helena quem decide o que será "leitura masculina". Talvez isso ocorra por já ter sido muito bem introjetado nela o papel social do homem e o da mulher - ela já havia mostrado que conhecia e dominava as regras do jogo.

Marisa Lajolo e Regina Zilberman apontam que "[...] se a educação das mulheres era vital para consolidar a revolução burguesa, ela também acarretava riscos, corporificados nos livros lidos, na cultura adquirida, na igualdade que se esboçava.. ${ }^{26}$ No Brasil, somente após a Independência é que a mulher virou consumidora de cultura impressa e é a partir de 1870 que se intensificam as campanhas pela educação feminina. Nessa época, a educação tornou-se o capital social das moças de classe média. As leitoras de papel e tinta, i. e., as personagens femininas, representam os hábitos de leitura existentes e estimulam outros. Assim, a representação da mulher leitora desenhava e reforçava seu lugar social.

Após o almoço, D. Úrsula descansa e lê, ${ }^{27}$ rejeitando companhia e o hábito da leitura coletiva, o qual remeteria o leitor da época às práticas coloniais, de corte patriarcal. Seu irmão, o falecido Conselheiro Vale, tinha um espaço diferenciado para fazer suas leituras - o gabinete, aquele que foi herdado por Estácio e é reorganizado pelos irmãos:

Estácio deu algumas indicações relativas ao teor da vida doméstica de seu pai; mostrou-lhe a cadeira em que ele costumava ler, de tarde e de manhã; os retratos [...]. Sobre a mesa, perto da janela, estava ainda o último livro que o conselheiro lera: eram as Máximas do marquês de Marica. Helena pegou nele e beijou a página aberta. ${ }^{28}$

A leitura "masculina" difere bastante da "feminina": o tipo de texto é outro - o texto "masculino" convida explicitamente à reflexão; o espaço destinado

25. MACHADO DE ASSIS, 1957, p.163-164.

26. LAJOlO; ZilBerman, 1996, p. 238.

27. MACHADO DE ASSIS, 1957, p. 33.

28. MACHADO DE ASSIS, 1957, p. 35. 
à leitura é reservado, prevendo autonomia e privacidade; os horários destinados à leitura são mais amplos - é como se a leitura "masculina" se justificasse por ser uma ocupação nobre.

A leitura "feminina" é, de certa forma, pública, ainda que feita na alcova, o que lhe dá um caráter de ato censurável, controlável, e se mistura a outros afazeres "femininos", como a complementá-los:

A notícia da volta de Mendonça encheu de contentamento o sobrinho de D. Úrsula. D. Úrsula estava então na sala de costura, relendo algumas páginas de seu Saint-Clair, encostada a uma mesa. Do outro lado, ficava Helena, a concluir uma obra de crochet. $^{29}$

É aí que Helena mostra certa independência de leitura: conta ao irmão que "furtara" um livro de seu gabinete - Manon Lescaut . Estácio reage:

- Oh! exclamou Estácio. Esse livro...

- Esquisito, não é? Quando percebi que o era, fechei-o e lá o pus outra vez.

- Não é livro para moças solteiras...

- Não creio mesmo que seja para moças casadas, replicou Helena rindo e sentando-se à mesa. Em todo o caso, li apenas algumas páginas. Depois abri um livro de geometria... e confesso que tive um desejo..."

O desejo de Helena era aprender a andar a cavalo - coisa que ela já sabia, apenas usou a geometria como pretexto. Mas sua atitude é ousada: de um lado, ela invade o gabinete - espaço masculino reservado - e escolhe um livro essa escolha não tivera autorização prévia; de outro lado, passa do romance à geometria, ambos "vetados" às mulheres, sendo o último um objeto de estudo "masculino". Helena parece representar a necessidade feminina de desenvolver táticas furtivas para ampliar seus horizontes literários e culturais. Embora ela retome a prática "borboleteante" de leitura, ou talvez até por ela, a qual também pode ser vista como uma tática de sobrevivência feminina no mundo masculino da leitura, Helena ousa romper os padrões já estabelecidos e que garantiriam a ordem patriarcal.

A "leitura masculina" pode ser considerada a leitura que sustentava a sociedade do século em questão, aquela que re-produzia os saberes e fazeres de

29. MACHADO DE ASSIS, 1957, p. 56.

30. MACHADO DE ASSIS, 1957, p. 58-59. 
uma sociedade eminentemente patriarcal. Já a "leitura feminina", apesar de ser "à luz do dia”, pode ser entendida como a leitura feita pelo viés da assimetria, indicadora de uma certa rebeldia, de uma outra sociedade, não tão patriarcal. E o fato de ser "borboleteante" a faz, antes de tudo, uma leitura que espalharia sementes, disseminaria hábitos de leitura, constituindo-se em uma forma de ler pela assimetria aquela sociedade tão impositiva, tão hegemônica.

Tanto Helena, que lê às escondidas em seu quarto, quanto D. Úrsula, têm na leitura a representação de uma certa rebeldia, de um fazer parodístico daquela sociedade. Se ler é responder a um outro, tanto uma, quanto outra respondem no seu ato de ler a esse outro - autor, leitor, estruturação sócio-economica - o ser masculino.

Abstract. This article studies the representations of reading acts presented in the novel Helena, by Machado de Assis, by assuming that these representations are tools capable of configuring the 18th-century Brazilian reader profile. In order to demonstrate this hypothesis, a comparative analysis is carried out concerning the scenes that are performed by D. Ursula, Helena and Estácio-, while taking into account social, political, and historical relations that involve the characters under investigation. We have noted "feminine" and "masculine" modes of reading, which permits one to reflect on the role played by women in Brazil in a patriarchal society, going through capitalism. The goal is to investigate the way this novel works in the formation and the maintenance of patterns of taste concerning literary reading. The whole argumentation is underpinned by theoretical developments of authors such as: Wolfgang Iser, Roger Chartier, Marisa Lajolo, Regina Zilberman, Hélio Guimaräes, among others.

Keywords: reading acts, literary representation, Machado de Assis, reader.

$$
\text { Referências }
$$

ARISTÓTELES. Poética. São Paulo: Abril, 1996.

ECO, Umberto. Seis passeios pelos bosques da ficção. Trad. Hildegard Feist. São Paulo: Companhia das Letras, 1994.

GUIMARÃES, Hélio de Seixas. Os leitores de Machado de Assis: o romance machadiano e o público de literatura no século 19. São Paulo: Nankin Editorial; EdUSP, 2004. 
ISER, Wolfgang. A interação do texto com o leitor. In: LIMA, Luiz Costa (Org.). A literatura e o leitor: textos de estética da recepção. Rio de Janeiro: Paz e Terra, 1979. p. 83-132.

LAJOLO, Marisa; ZILBERMAN, Regina. A formação da leitura no Brasil. São Paulo: Ática, 1996.

LAJOLO, Marisa. Como e por que ler o romance brasileiro. Rio de Janeiro: Objetiva, 2004 .

LYONS, Martyn. A história da leitura de Gutenberg a Bill Gates. In: LYONS, Martyn; LEAHY, Cyana. A palavra impressa: histórias da leitura no século XIX. Rio de Janeiro: Casa da Palavra, 1999. p. 7-22.

MACHADO DE ASSIS, Joaquim Maria. Helena. Rio de Janeiro: Jackson, 1959.

Iaiá Garcia. Rio de Janeiro: Jackson, 1959.

Memórias póstumas de Brás Cubas. Rio de Janeiro: Jackson, 1957.

OLSON, David R. O mundo no papel: as implicações conceituais e cognitivas da leitura e da escrita. Trad. Sérgio Bath. São Paulo: Ática, 1997.

PINA, Patrícia K. C. Literatura e jornalismo no oitocentos brasileiro. Ilhéus: Editus, 2002 .

PINA, Patrícia K. C. A crônica na imprensa periódica oitocentista: Machado de Assis e a formação do público leitor. Revista Brasileira de Literatura Comparada. Rio de Janeiro, n. 9, p. 65-78, 2006.

SCHWARZ, Roberto. Ao vencedor as batatas: forma literária e processo social nos inícios do romance brasileiro. São Paulo: Duas Cidades, 1981.

WALTY, Ivete Lara Camargos; FONSECA, Maria Nazareth Soares; CURY, Maria Zilda Ferreira. Palavra e imagem: leituras cruzadas. Belo Horizonte: Autêntica, 2006.

ZILBERMAN, Regina. Estética da recepção e história da literatura. São Paulo: Ática, 1989.

ZUMTHOR, Paul. A letra e a voz: a "literatura" medieval. Trad. Amalio Pinheiro e Jerusa Pires Ferreira. São Paulo: Companhia das Letras, 1993. 